\title{
ALGUNAS REFLEXIONES SOBRE EL COLECCIONISMO
}

Guillermo de Osma

Historiador del Arte y galerista 

Mi intervención se va a centrar en algunos aspectos del coleccionismo desde tres puntos de vista del galerista que soy, pero también desde el coleccionista. Llevo haciendo una colección ecléctica, centrada sobre todo en el arte moderno desde hace más o menos treinta años. El tercer punto de vista es como presidente de la Fundación Bemberg en la ciudad de Toulouse, que abrió sus puertas como museo hace veinte años, con una colección muy extensa e histórica, pues empieza en el Renacimiento y acaba con Bonnard. Es una colección abierta y que sigue adquiriendo obra activamente pero de una manera muy selectiva condicionada por la falta de espacio. Me voy a centrar en el coleccionismo de arte moderno y contemporáneo.

\section{UN POCO DE HISTORIA}

Para entender el coleccionismo, y en este caso me refiero al español, creo que es fundamental conocer un poco de dónde venimos y dónde estamos. Me gustaría mucho poder contarles adónde vamos, pero eso nos lo dirá la historia.

Me parece importante hacer hincapié en que la historia del arte moderno empieza en España en dos galerías de arte con sendas exposiciones emblemáticas. Y aprovecho aquí para insistir sobre el papel de la galería, no solo como intermediaria entre el artista y el público y como espacio cultural donde podemos contemplar exposiciones de todo tipo y estilo, sino como agente fundamental de la introducción, en este caso en España, del arte de vanguardia adelantándose a las instituciones y museos, en todo caso hasta tiempos recientes.

La primera exposición que abre al público español al arte moderno tuvo lugar en 1912 en la Sala Dalmau de Barcelona, bajo el título de Arte cubista. Allí se expuso uno de los cuadros más emblemáticos del siglo xx, el Desnudo bajando las escaleras de Duchamp y que desgraciadamente a ningún coleccionista se le pasó por la cabeza adquirirlo. Tampoco, que yo sepa, se adquirieron obras de los otros participantes en la exposición: Albert Gleizes, Juan Gris y Jean Metzinger, entre otros.

La segunda exposición que inaugura el arte moderno en España fue la Exposición de «los Pintores Íntegros», organizada por Ramón Gómez de la Serna en el Salón Arte Moderno en Madrid en 1915, donde participaron María Blanchard, Diego Rivera, Luis Bagaría y un escultor naif. El Salón Arte Moderno no tuvo ninguna otra actividad y en mi opinión fue una sala que alquiló Gómez de la Serna para esta ocasión, poniendo en evidencia que en Madrid no había ninguna galería de arte moderno. Las primeras abrieron sus puertas justo después de la Guerra Civil, lo cual, aunque sorprendente, es absolutamente cierto. Los pintores de esa generación, la generación de los Ibéricos y de la primera Escuela de París, tuvieron que exponer en lugares alternativos como fueron el Salón de los coches Chrysler, los locales del periódico El Heraldo de Madrid, la Asociación de Amigos del Arte o, como en el caso de Maruja Mallo, en la Revista de Occidente bajo la tutela de Ortega y Gasset, siendo la única exposición que organizó.

En Barcelona, ciudad más europea y puesta al día, sí hubo varias galerías que exponían artistas de avanzada, como Layetanas y, de una manera muy sobresaliente, las galerías Dalmau, dirigidas por ese personaje extraordinario y heroico que fue José Dalmau (1867-1937). A lo largo de las décadas de 1910 y 1920 expuso a muchos de los artistas fundamentales de la vanguardia, tanto española como europea, entre muchos otros a Barradas, Torres-García, Miró y Dalí; entre los europeos destacan los Delaunay, Marinetti, Van Dongen y Picabia, con su emblemática exposición de 1922. 
A pesar de la extraordinaria labor de Dalmau, yo no tengo constancia de que en Barcelona se hiciera una colección del arte de vanguardia que él exponía, y Dalmau acabó su vida arruinado en 1937.

Las pocas colecciones reunidas de las que tenemos constancia en esos años son lo que podríamos llamar "colecciones de amigo»; la más conocida fue quizá la de Federico García Lorca, que fue motivo de una exposición en la Residencia de Estudiantes de Madrid hace unos años. En su colección había varias obras importantes de Salvador Dalí, como el famoso bodegón que presidía su cuarto de la Residencia, y también obras de sus amigos y compañeros de La Barraca, como Palencia, Ponce de León, Ismael Gómez de la Serna, Barradas, Caballero, Norah Borges, Ángeles Ortiz, etc.

Sabemos también que Cernuda tenía algún cuadro de Moreno Villa, Altolaguirre tenía un bodegón cubista de Manuel Ángeles Ortiz y José María Hinojosa poseía otra interesante colección.

La más importante de las que se hicieron esos años fue la del pintor Alfonso Olivares. Este conjugaba el interés y la pasión del coleccionista con las posibilidades económicas — la fórmula ideal—y reunió obras de Picasso, Gris, Vázquez Díaz, Moreno Villa y sus amigos de la Escuela de París, como Viñes, Cossío, Peinado, Ángeles Ortiz y Gómez de la Serna. Colección que él publica en el precioso libro Arte moderno, editado primorosamente por Manuel Altolaguirre, donde reúne junto a sus escritos y colección, su trabajo como arquitecto de interiores y pintor.

En los primeros años de 1930, en el Museo de Arte Moderno, bajo la dirección del crítico Ricardo Gutiérrez Abascal, alias Juan de la Encina, se llevó a cabo una puesta al día y se organizaron exposiciones de Norah Borges, Max Ernst, García Maroto, Benjamín Palencia y Torres-García, pero no se incorporó a la colección ninguna obra de estos artistas, representantes de la modernidad.

Es importante destacar en esta década la iniciativa de la sociedad civil a través de asociaciones de apoyo al arte moderno, en la que destaca ADLAN (Amigos del Arte Nuevo), creada en Barcelona en 1932 de la mano de Joan Prats, el arquitecto José María Sert (en su colección sabemos que había, entre otros, una obra de Maruja Mallo), Dalí, Ángel Ferrant, etc. ADLAN tuvo sede también en Madrid y más tarde en Tenerife, y en sus salas expusieron el «Circo» de Calder, Miró, Ferrant, Arp, Maruja Mallo, Man Ray, etc., y organizaron la primera retrospectiva española de Picasso, que viajó de Madrid a Bilbao y Barcelona.

La guerra supuso una ruptura brutal en la modernización de la plástica en España. Habría que esperar al año 1939, que con el final de la guerra permitiría el desarrollo del galerismo moderno en nuestro país. Y entre 1939 y 1945 veríamos aparecer en Madrid — donde no había habido hasta ahora una sola galería de arte moderno- una serie de galerías fundamentales como Biosca, la galería Estilo de José María Peña, Buchholz, el Salón Cano, la Sala Macarrón, la galería Palma y la galería Clan. Es bastante sorprendente que en estos años duros de la posguerra floreciera este galerismo y naciera el primer coleccionismo de arte moderno en España. Es como si la sociedad civil tomara las riendas de la cultura y la iniciativa en la normalización de la vida cultural y la apertura a criterios artísticos más novedosos. Al mismo tiempo, esta misma sociedad civil empezará también las primeras y tímidas colecciones de arte contemporáneo. Los años 50 son una década decisiva para este proceso de normalización. En 1951 (decreto del 9 de octubre), el Museo de Arte Moderno se divide entre Museo del XIX y el Museo de Arte Contemporáneo. Este último será dirigido por un personaje genial, el arquitecto José Luis Fernández del Amo, de 1951 a 1959. Será responsable de la creación de la sorprendente Sala Negra, en Recoletos 2 de Madrid, que, como su nombre indica, era un espacio pintado de negro, donde en 1957 organiza la fundamental exposición Otro arte, donde se pueden ver en Madrid obras de todos los grandes nombres abstractos españoles e internacionales, incluidos Rothko y Pollock. Son los años de la presencia de los éxitos de los abstractos españoles en las Bienales Internacionales, el apoyo de familias empresarias como los March y los Huarte a los artistas jóvenes, los primeros acabarían creando la Fundación Juan March y los últimos patrocinando a Chillida, Oteiza y Palazuelo; Fernando Zóbel empieza su colección de arte abstracto, que culminará con la apertura del Museo de Arte Abstracto de Cuenca en 1966. El Museo de Bilbao sorprende en 1960 con la compra de un Tàpies matérico. 
Todo esto va generando a lo largo de la geografía española una estructura de galerías, exposiciones, revistas, críticos y coleccionistas a semejanza de otros países europeos. Puesta al día que se acelera en los 60 y 70 (la emblemática galería de Juana Mordó abre sus puertas en 1964) y aparecen las primeras colecciones corporativas. Este proceso se normaliza completamente con la Transición y con la aparición en el año 1982 de la Feria ARCO.

Esta feria va a jugar un papel decisivo en el acercamiento del arte contemporáneo a nuestra sociedad y, en mi opinión, es la institución que más ha hecho en este país, más que los museos, por el arte contemporáneo y su coleccionismo. ARCO ha ayudado a que el público le pierda el miedo a acercarse al arte de vanguardia sin que tanto el artista como las galerías pierdan su carácter profesional e independiente. Se podría decir que el arte contemporáneo, gracias a ARCO, ha llegado a formar parte de nuestras vidas y así se ha terminado de recorrer un camino que parecía tan difícil de remontar. En cualquier caso, la falta de tradición coleccionista pesa mucho en nuestro país y es sin duda una de las causas del coleccionismo relativamente pobre e inconstante. También a nivel del Estado y de las colecciones de museos y fundaciones, que se han encontrado con enormes huecos y muchas dificultades para incorporar obras que suplan todas esas carencias dada la evolución de precios tan fuerte que ha habido en el mercado en los últimos años.

En este contexto, la Galería Guillermo de Osma hace su aparición en 1991 con una voluntad muy clara de revisar la vanguardia histórica española, europea y latinoamericana. Iniciamos nuestra andadura con la exposición «Torres-García - Barradas» (la primera de Barradas en España desde su fallecimiento en 1929) acompañada de un importante catálogo donde publicamos la correspondencia inédita de Torres y Guillermo de Torre, que marcaría el tono de las 80 exposiciones y catálogos que han seguido a esta. Ser galerista, profesión a la que al principio miraba, con el prurito del historiador, con cierto recelo, me ha dado una enorme independencia y muchas satisfacciones. La semilla de muchos artistas que he presentado: Maruja Mallo, Óscar Domínguez, Barradas, Manuel Ángeles Ortiz, etc., ha visto su fruto posteriormente en exposiciones antológicas en los grandes museos.

La galería es como una hidra con dos cabezas. Es un comercio y como tal debe ser rentable, lo que a menudo supone un desafío que no siempre es fácil, pero que obliga a aguzar el ingenio, avanzarse al gusto del momento y mirar siempre adelante. La galería es al mismo tiempo un espacio cultural gratuito y abierto al público, que ofrece una variedad extraordinaria de exposiciones con arte de todo tipo.

El galerista es un puente necesario ente el coleccionista, el crítico, el conservador, el público y el artista. Pero es algo más que un intermediario. El galerista tiene que tener el don de elegir y decidir lo que va a defender entre miles de artistas de todo el planeta y, además, ser capaz —o intentarlo— de predecir y adivinar el futuro. No solo debe saber presentar e interpretar, sino también entender el espíritu de lo que expone y hacerlo accesible.

Tener una visión, saber elegir y acertar, facilitar la comunicación y la comprensión del artista con el resto de los mortales solo puede ser cosa de magos.

Como coleccionista y galerista — caras de la misma moneda — quería compartir algunos conceptos y reflexiones sobre el tema que nos ocupa.

\section{LA COLECCIÓN COMO UN MICROCOSMOS}

Coleccionar es una actividad muy extendida y común desde hace siglos. Se puede coleccionar de todo, desde cajas de cerillas o sellos hasta grandes obras maestras, pero esta no deja de ser una ocupación extraña, ya que se trata de enajenar los objetos de su contexto o de su función para reunirlos en un espacio nuevo estableciendo relaciones nuevas y estrechas con otros objetos a los que el coleccionista otorga nuevos significados marcados por su personalidad y la de la propia colección. Por esta misma razón es una actividad apasionante, lo mismo que su estudio. 
Coleccionar es una forma de comportamiento, una manera de entender la vida y de estar en el mundo. Tiene mucho de actitud vital ligada inevitablemente al ego del que colecciona, hay mucho de psicológico en este fenómeno, asunto en el que no voy a entrar ya que no tengo ese conocimiento, pero sí creo que refleja una cierta filosofía de vida ligada sin duda al hecho de primar la estética y el goce de los objetos sobre otros aspectos de la vida.

La colección tiene mucho de creación, creación personal. Como decían los hermanos Goncourt, coleccionistas ellos mismos y de los primeros teóricos sobre coleccionismo, es la colección la que debe llevar la firma del coleccionista y no los objetos individualmente. La colección debe reflejar la personalidad del que la ha hecho. Y no solo su personalidad, sino también su gusto tanto en la elección de los objetos, en la manera de presentarlos, su cultura, sus conocimientos y su poder, tan relacionado con su ego. Esta actitud es, como ya hemos dicho, una manera de estar en el mundo, pero sobre todo de crear uno propio: un microcosmos. Este microcosmos que refleja su personalidad da lugar a la necesidad de crear un espacio especial para la colección, un espacio distinto y al que poder retirarse del mundanal ruido. Esta consideración de la colección como retiro está en el origen de las Wünderkammer (cámaras de las maravillas), de los siglos XVı y xVII, de los primeros museos o de las mansiones de la gran burguesía, llenas de objetos artísticos. Hoy en día vemos cómo esas mansiones se trasladan a almacenes industriales, donde el coleccionista actual acumula las obras más variadas en técnicas y estilos de la creación contemporánea.

Coleccionar tiene mucho de pasión y, como toda pasión, está cercana al caos. Por eso, la necesidad de ordenar ese microcosmos con un criterio que puede ser muy estricto — conocí a un coleccionista que en su casa decorada de blanco solo tenía tres objetos artísticos, una escultura griega, un mueble francés que procedía de Versalles y un cuadro de Mondrian - o muy ecléctico y agorafóbico. Ordenar ese caos es una tendencia natural de toda colección y es muy normal que haya un registro razonado de las obras que la componen, un catálogo. Entre la aspiración al orden de casi toda colección y la imposibilidad de acabar de completarla — siempre falta algo o se quiere poseer lo que no se tiene- se genera una tensión que incita al coleccionista a seguir buscando con instinto cazador su siguiente presa y así intentar completar el microcosmos que ha creado.

\section{LA DISTANCIA ÍNTIMA}

El coleccionista necesita conectarse con nociones familiares pero al mismo tiempo ajenas. Para resultar atractivo, un objeto debe ser a la vez conocido y desconocido. Esta cualidad paradójica es lo que algún crítico ha llamado «distancia íntima».

Es muy raro que un coleccionista compre algo completamente desconocido para él, pero, si es un verdadero coleccionista - no un comprador de cuadros y menos aún un especulador-, le atraerá la idea de alejarse un poco o mucho de su territorio familiar de coleccionismo y de explorar, con la curiosidad innata de todo coleccionista, territorios colindantes. Y, así, crear nexos, ampliar las fronteras de su colección. Muchos coleccionistas trabajan como una araña — la araña de Louise Bourgeois - tejiendo su tela como una red, creando una estructura de vínculos sólidos. Esto puede producirse en una colección muy centrada y con un criterio restringido como la colección Patricia Phelps de Cisneros de arte geométrico latinoamericano o una colección como la de Yves Saint-Laurent, mucho más ecléctica y enciclopédica pero construida de la misma manera. Un cuadro o una obra lleva a otra y esta a otra. Ese cuadro desconocido, pero en cierto modo no del todo, permite abrir la colección y llevarla por nuevos caminos que pronto serán familiares y formarán parte de esa red, de esa tela de araña, de ese microcosmos que es toda colección viva.

\section{EL ARTE FÁCIL O EL FÁCIL ARTE: ¿UN NUEVO ACADEMICISMO?}

El arte moderno entendido como vanguardia es de por sí un arte desafiante, provocador e innovador. Aspira a jugar un papel de fomentar el diálogo entre el artista y el espectador provocándolo y creando por ese mismo hecho una 
reacción de incomprensión o rechazo por parte del espectador. En general ha sido un arte de difícil aceptación. Arte de su tiempo, convulso, con una ambición de transformar el hombre y la sociedad: el hombre nuevo de los artistas utópicos y revolucionarios desde el Constructivismo ruso a la Bauhaus.

En el arte moderno es el espectador el que tiene que hacer un esfuerzo por entender el lenguaje del artista y ponerse a su nivel. Es un arte difícil, a menudo hermético, de difícil comprensión, por esas razones fue incomprendido en su momento, rechazado por gran parte de la crítica y la mayoría del público. Al final pecó de la paradójica contradicción de querer ser un arte para las masas y acabar siendo un arte de la élite.

Sus primeros apoyos vinieron fundamentalmente de los galeristas, galeristas heróicos como Dalmau en España, Kanhweiler en Francia, Flechtheim en Alemania, Marius de Zayas en Nueva York. A estos siguieron algunos conservadores de museos y coleccionistas atrevidos, los Stein, Phillips, Katherine Dreier, Alfonso Olivares, etc., todos ellos de clase alta, con ciertos medios y una esmerada educación.

A finales del siglo xx hay una evolución que hace del arte contemporáneo un caso particular y —en cualquier caso para mí- difícil de entender: es su aceptación casi inmediata por el público aficionado y en particular por el coleccionista. De alguna manera el arte ha perdido esa capacidad provocadora y consiguientemente distanciadora para hacerse cercana y en cierta manera inofensiva. Esto obviamente facilita enormemente su venta y comercialización. Incluso artistas complejos, como Robert Gober, los hermanos Chapman o los primeros tiburones de Hirst son aceptados sin problemas y de manera casi inmediata por el coleccionista, las instituciones y el público en general.

En los últimos veinte años se ha acelerado el progresivo interés por el arte contemporáneo. Habría que remontarse a épocas pasadas para encontrar artistas tan populares y que forman parte del entramado social, como Koons, Christopher Wool, Hirst, etc., aprendices de Warhol. Me hacen pensar en el gran arte académico de los pintores de salón y los concursos nacionales de finales del siglo xIX como Bouguerau, Cabanel o, entre los españoles, el éxito internacional de un Mariano Fortuny y, más tarde, de un Sorolla. Lejos queda el artista marginado y revolucionario de los años 20 hasta la década de los 60.

¿El arte realmente se ha hecho fácil o simplemente accesible? ¿Ha perdido su carga virulenta y hermética, o somos más cultos e informados? En todo caso, esta facilidad que tiene el artista y el arte contemporáneo para mostrarse y formar parte de nuestra vida de ocio y de cultura invita a dos cosas. Por un lado, a la proliferación de galerías, centros expositivos, museos de arte contemporáneo, casas de subastas, críticos, comisarios, bienales, etc., es decir, del mercado. Por otro lado, a una mayor complicidad entre todos estos actores. Complicidad compleja y cómplice. Por una parte, los roles dejan de tener un papel definido como en el pasado, se difuminan y se pervierten. El crítico se convierte en asesor, el coleccionista (un Saatchi o un Pinault, dueño de Christie's) se convierte en marchante, las nuevas 'mega galerías' (Gagosian o Zwirner) organizan exposiciones de museo, etc. Por otra parte, hay una sinergia entre todos estos actores que tiene una clara influencia a la hora de confeccionar el who is who de los artistas del momento, la lista de los «40 principales» y quiénes deben subir y quiénes bajar.

Es evidente que todo esto no sería posible sin la complicidad del artista, al que siempre dejamos de lado en cuestiones de mercado, pero ya no es así. El artista navega en estas mismas aguas y en el mismo barco y juega el mismo juego.

\section{LA LOCURA DE LOS PRECIOS, EL CASO ESPAÑOL}

Esta hiperactividad del mercado y sus protagonistas ha llevado a la reciente locura de precios. Un cuadro de Christopher Wool se vendió hace poco en 28 millones de dólares, precios que han alcanzado y superado artistas como Koons, Richter, Warhol y otros. Cualquier artista de la escena internacional que tenga un cierto recorrido pero todavía en sus cuarentas o cincuentas no es nadie si no vale al menos un millón de dólares. Parece evidente que es una situación muy difícil de sostener y que muchos coleccionistas que han entrado en este juego de 
comprar lo que está de moda, los «40 principales», que por supuesto cambiarán en pocos años, van a sufrir una pérdida muy importante del valor que han pagado de una manera tan irresponsable. En los años 80, en los que viví en Nueva York, la galería que hacía la ley y que muy pocos de ustedes recordarán era Mary Boone, llevaba a los tres artistas más cotizados del momento: Julian Schnabel, David Salle y Eric Fischl. Este último llegó a valer en los 80 un millón de dólares, que era lo que valía un buen cuadro de Picasso. Hoy en día ese mismo cuadro vale alrededor de un tercio de ese valor.

Esto contrasta brutalmente con el desolador panorama del mercado español actual, que sigue sin recuperarse y donde no solo los precios han bajado mucho, sino que es difícil encontrar un comprador para nuestros artistas. Es fundamental para remediar esta situación que entre todos -instituciones, Estado, galeristas, coleccionistas y críticos - internacionalicemos la creación española. Como ya hemos comentado antes, sin duda nuestra pobre tradición y la falta de educación son factores importantes en esta ensombrecida situación. La legislación estatal sobre Patrimonio y obras de arte es torpe y poco generosa, con tasas e impuestos de todo tipo que no invitan al desarrollo del coleccionismo. Lo que se traduce en un detrimento en el Patrimonio artístico del Estado.

\section{EL ARTISTA CONTEMPORÁNEO COLECCIONA EL PASADO}

Al convertirse el artista exitoso en un hombre rico y poderoso se ha transformado lo que hemos llamado «colección de amigo» en colecciones más ambiciosas y amplias con vocación casi institucional, como la de un Botero, en la que están representados muchos de los grandes nombres del siglo xx.

Últimamente con la locura de los precios y el dineral que hacen muchos artistas se está produciendo un giro sorprendente. El artista de éxito no solo no compra el arte contemporáneo ni a sus contemporáneos, sino que mira para atrás y se interesa por el arte de épocas pasadas. Así, Chuck Close colecciona pintura y retratos del siglo xVII, Wim Delvoye es un frecuente visitante de subastas y anticuarios, Howard Hodgkin colecciona pintura india y mohul, George Baselitz estampas manieristas, Jasper Johns ha reunido una importante colección de obras cubistas, Damian Hirst adquiere obras sobre el tema de la muerte que relaciona con su obra, George Condo retratos antiguos y Jeff Koons ha estado muy activo coleccionando cuadros y esculturas del siglo xv al xIx como Quentin Matsys, Poussin, Fragonard, Coubert y hasta Dalí.

¿Parece que todos ellos nos quieren decir que desconfían en todo caso de los precios del arte actual y quizá también de una parte de la creación de sus contemporáneos?

\section{LA MONETARIZACIÓN DEL ARTE}

Todo esto nos lleva al complejo capítulo del arte como inversión. En las últimas décadas parece que el arte y el dinero, sino son la misma cosa, son primos hermanos que cada vez se parecen más. Esto provoca reacciones. Una evidente es el precio del arte y el impacto que tiene en la mente del público. Los resultados de las grandes subastas saltan a las primeras páginas de los periódicos y los récords astronómicos son noticia que llega a millones de personas, incluso a las totalmente ajenas o a las que jamás pueden acceder a una modesta obra de arte. Este factor, «lo que cuesta el arte», ya es algo público. Ha dejado de ser patrimonio de los iniciados: galeristas y coleccionistas. Hoy día con Internet podemos saber — con sus sutilezas y diversas lecturas - el precio de cualquier obra y de cualquier artista, y esto está cambiando el mercado y el funcionamiento tradicional, basado en el trinomio artista (productor)-galerista (intermediario)-público coleccionista o no (el receptor).

El otro aspecto es más sutil y para mí difícil de explicar. Este fenómeno de la monetarización del arte, en que la obra artística se ha ido confundiendo con su valor, de alguna manera ha tenido una contrapartida en un proceso de desmaterialización de la economía. Es como si a través de la ayuda y la difusión artística se pudiera 
espiritualizar, elevar a una altura extra económica, la propia actividad económica. Es, en cierta manera, como el pago por una penitencia. Si antes los poderosos compraban bulas, ahora compran cuadros o apoyan la promoción cultural.

Claramente este ha sido uno de los fenómenos más llamativos de los últimos 50 años, desde que David Rockefeller — personaje clave en la creación del MoMA — comenzara a crear una colección para el Banco Chase Manhattan en 1959. Muchas grandes corporaciones se apuntaron a esta tendencia, proceso que se acelera y se internazionaliza en los años 70 y 80 . En España muchos de los grandes bancos, empezando por el Urquijo -que acabaría formando parte del Santander-, el Banco Zaragozano, el BBV, Telefónica, Aena y las diferentes cajas han hecho colecciones importantes y mantienen fundaciones muy activas. En EE.UU. la legislación ha sido muy favorable a este fenómeno de mecenazgo, tanto corporativo como privado; en España desgraciadamente estamos muy retrasados y sería fundamental que hubiera una buena ley de mecenazgo para que la sociedad civil y empresarial pueda compensar y apoyar la labor cultural del Estado con las últimas reducciones presupuestarias.

En los últimos veinte años hemos visto también la aparición de un proceso nuevo: la de grandes museos personales creados por esta nueva generación de mega coleccionistas. Este es el caso del museo, abierto recientemente, por Ely Broad en Los Ángeles, los que Pinault abrió en el Palazzo Grassi y la Punta della Dogana en Venecia, o el museo de Bernard Arnault en París, obra del arquitecto Frank Ghery.

\section{PROTAGONISMO DEL COLECCIONISTA CONTEMPORÁNEO}

El coleccionista contemporáneo es más consciente que nunca de su contribución — fundamental y necesaria— en el mundo cultural actual y quiere jugar un papel mucho más activo. Está determinado a ser un jugador importante que quiere y tiene mucho que decir en este campo. No me refiero a la especulación en la que Saatchi ha sido un alumno aventajado, sino del coleccionista con un proyecto serio. Es evidente que el interés por el arte contemporáneo confiere y aumenta el prestigio social, pero hoy se podría decir que para muchos coleccionistas se ha convertido en un estilo de vida, una «semi religión» que mezcla estética, moral y economía. Es, a menudo, una estética basada en principios cuantitativos, donde arte y dinero son caras de una misma moneda cada vez más difícil de separar.

A todo este mundo le rodea una serie de ritos y comportamientos, como si de iniciados de una extraña secta se tratara. Comportamientos que se reflejan en una cierta manera de vestirse, en las obligadas visitas a las grandes ferias con una necesaria tarjeta VIP en la mano, en el recíproco cortejo a los mega galeristas, en la corte de asesores o conservadores que le rodean, etc. En España es todo más modesto y no es fácil encontrar ese tipo de ejemplos. La ley española dificulta enormemente con impuestos, gravámenes y la falta de una ley de mecenazgo suficientemente generosa la creación de grandes colecciones, la publicidad de las mismas y, por consiguiente, la posibilidad de realizar la vocación pública que tienen muchas colecciones importantes de constituirse en fundaciones o museos.

Estas reflexiones abordan, desde facetas diferentes, el fascinante y complejo fenómeno del coleccionismo al que el galerismo está tan íntimamente ligado.

En último término, el coleccionismo a todos sus niveles y con todas sus variantes es vital no solo para el artista, sino para la propia comunidad en la que se desarrolla. Es en sí un agente cultural activo y un elemento fundamental para la creación y el enriquecimiento del patrimonio artístico. 